\title{
Nail Fluorescence in COVID-19 Patients
}

\author{
Guder $\mathrm{H}^{1}$ and Ozunal $\mathrm{ZG}^{2 *}$ \\ ${ }^{1}$ Department of Dermatology, Faculty of Medicine, Maltepe University, Istanbul, Turkey \\ ${ }^{2}$ Department of Medical Pharmacology, Faculty of Medicine, Maltepe University, Istanbul, Turkey
}

Submission: December 12, 2020; Published: January 05, 2021

*Corresponding author: Ozunal ZG, Department of Medical Pharmacology, Faculty of Medicine, Maltepe University, Istanbul, Turkey

\section{Introduction}

On social media platforms, users posted fluorescence nails in COVID-19 patients [1]. Web-based news also reported that this finding is linked to the possibility of a side effect. Drug safety information in social media can gather data for pharmacovigilance, the science and activities relating to the detection, assessment, understanding and prevention of adverse effects or any other drugrelated problem [2]. In pandemics, medicines that are available at short notice need for close monitoring for pharmacovigilance aspects. We aimed to explore the nails of COVID-19 diagnosed patients to distinguish fluorescence presence at fingernails. In patients diagnosed with COVID-19, we examined the fingernails with the Wood's lamp in who received and did not receive favipiravir treatment, and evaluated fluorescent. We evaluated the time between the start of COVID-19 diagnosis or favipiravir treatment and the time of Wood's light examination. We further inquire about the 3-month history of drug intake [3]. Written Informed Consent is taken from cases. Health records and images are de-identified.

\section{Cases}

Six COVID-19 patients are evaluated. Gender, age, interval between COVID-19 diagnose and inspection, medication history is shown in Table 1. A bright blue fluorescence was not observed on the fingernails of the $1^{\text {st }}$ patient, who was our only patient who did not receive favipiravir (Figure 1). Our second patient, who received favipiravir 42 days ago, had a 4-month history of using the antituberculous treatment for renal tuberculosis. The patient's fingernails had blue fluorescence across the entire nail plate, and this blue fluorescence was more pronounced at approximately $3 \mathrm{~mm}$ of the proximal nail plate (Figure 2). Patient 3 had received favipiravir treatment twice, 126 and 22 days ago (Figure 3). There was approximately $1 \mathrm{~mm}$ finger blue fluorescence in the proximal nail plate of the patient's fingernails. The absence of bright blue fluorescence in the distal part of the nail plate of the patient may suggest that the traces of previous favipiravir treatment have disappeared. Patient 4 had received favipiravir treatment 32 days ago, and a bright blue fluorescence of approximately $2 \mathrm{~mm}$ was observed in the proximal nail plate (Figure 4). Patients 5 and 6 had received favipiravir treatment 15 and 16 days ago. Approximately $1 \mathrm{~mm}$ of bright blue fluorescence was observed in the proximal part of the nail plate of the patients (Figures $5 \& 6$ ).

Table 1: Gender, age, COVID-19 diagnose, and inspection interval,

medication history is given.

\begin{tabular}{|c|c|c|c|c|}
\hline Patient & M/F & Age & $\begin{array}{r}\text { COVID-19 diagnose and } \\
\text { inspection interval }\end{array}$ & Medication History \\
\hline 1 & M & 39 & 10 days & $\begin{array}{c}\text { Enoxaparin, Vitamin B Complex and Vitamin C Ampule, Pantoprazole 10 } \\
\text { days for COVID-19 Ceftriaxone, Vancomycin, Fluconazole for lung abscess } \\
\text { Chlorpromazine, haloperidol for autism and agitation N acetylcysteine, Urso- } \\
\text { deoxycholic acid for supportive therapy }\end{array}$ \\
\hline 2 & M & 44 & 42 days & $\begin{array}{r}5 \text { days Favipiravir, Enoxaparin, Vitamin B Complex and Vitamin C, Pan- } \\
\text { toprazole 42 days ago for COVID-19 isoniazid, rifamycin, ethambutol, and } \\
\text { pyrazinamide for 4 months for renal tuberculosis }\end{array}$ \\
\hline 3 & F & 22 & 126 days and 22 days & $\begin{array}{r}5 \text { days Favipiravir 126 days ago for COVID-19 } \\
5 \text { days favipiravir, 16 days Enoxaparin, Vitamin B Complex and Vitamin C, } \\
\text { Pantoprazole 22 days ago for COVID-19 }\end{array}$ \\
\hline 4 & M & 42 & 32 days & 5 days Favipiravir, 14 days Enoxaparin, Vitamin B Complex and Vitamin C 32 \\
days ago for COVID-19
\end{tabular}




\section{Juniper Online Journal of Dermatology \& Cosmetics}

\begin{tabular}{|c|c|c|c|c|}
\hline 5 & F & 36 & 15 days & $\begin{array}{c}5 \text { days Favipiravir, } 14 \text { days Enoxaparin, Bisoprolol Fumarate for } 2 \text { months for } \\
\text { arrhythmia }\end{array}$ \\
\hline 6 & F & 35 & 16 days & Only 5 days Favipiravir,16 days ago for COVID-19 \\
\hline
\end{tabular}

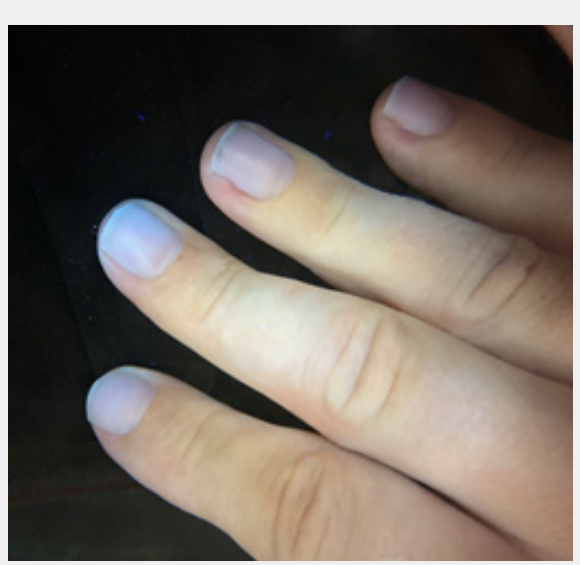

Figure 1: Fingernails examined with Wood's lamp. Patient 1.

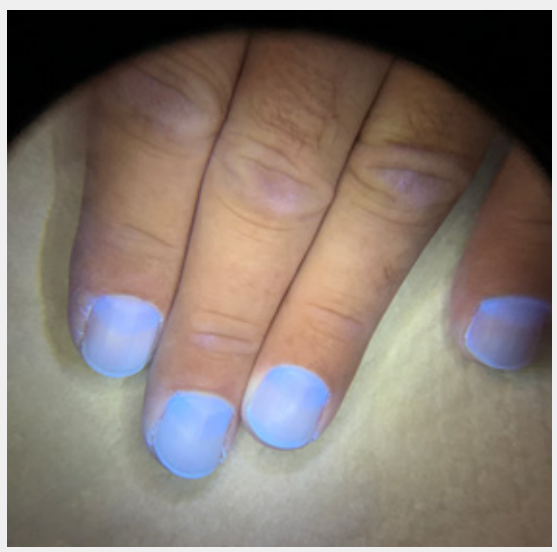

Figure 2: Fingernails examined with Wood's lamp. Patient 2.



Figure 3: Fingernails examined with Wood's lamp. Patient 3. 


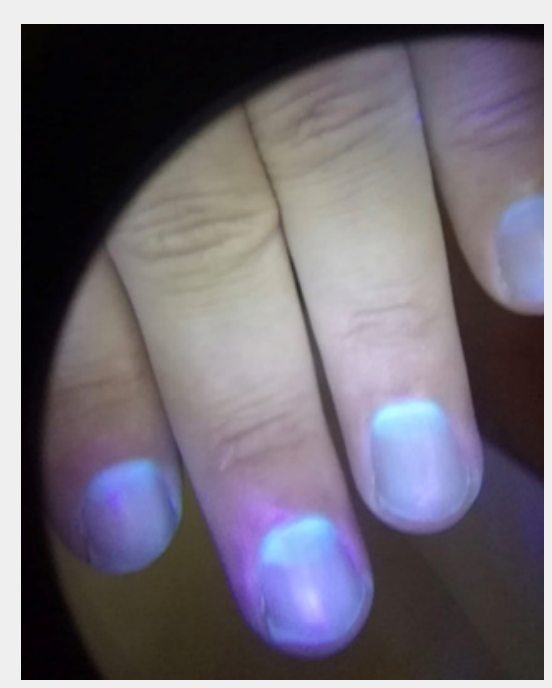

Figure 4: Fingernails examined with Wood's lamp. Patient 4.

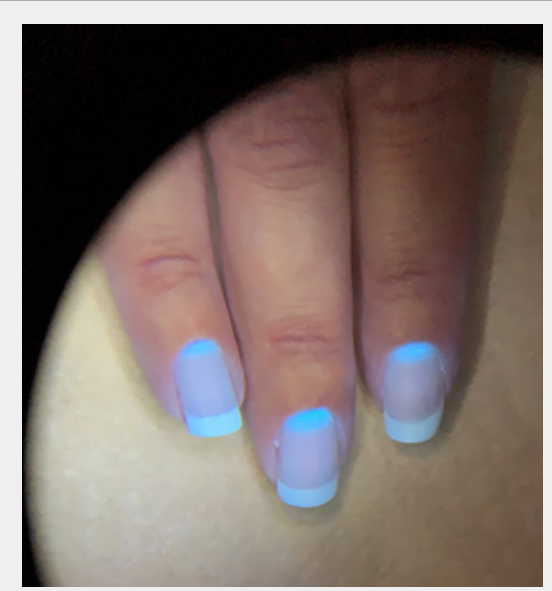

Figure 5: Fingernails examined with Wood's lamp. Patient 5.

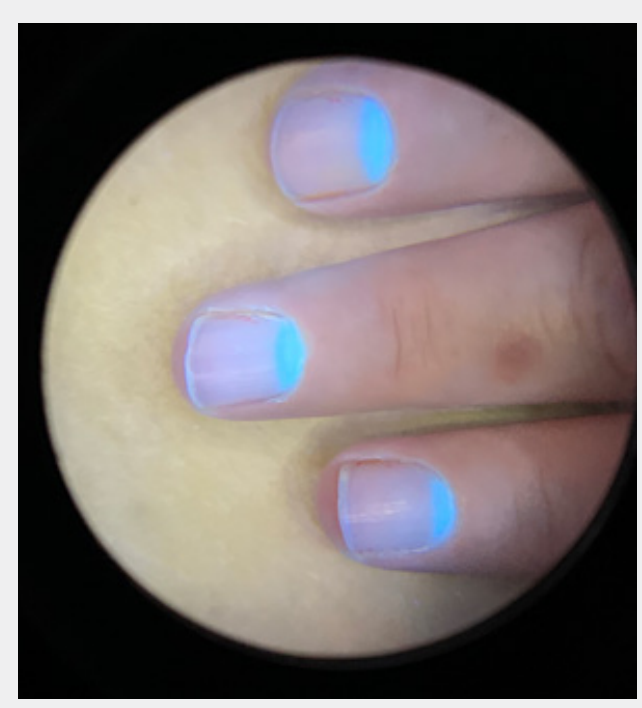

Figure 6: Fingernails examined with Wood's lamp. Patient 6. 


\section{Discussion}

The nail is a keratinous skin appendage that grows 2-3 mm per month. It takes approximately 6-9 months for a nail to replacement completely. The colour change seen in the nail is called chromonychia. When the colour change is white, this is specifically called leukonychia. It has been reported that there is a bluish discolouration in the lunula (distal nail matrix) due to excess copper accumulation from Wilson's disease. Due to the collection of silver salts in Argyria, there is a blackish grey colour change in the lunula. Transverse leukonychia is seen as lines with opaque white bands on the nail. Measuring the length of the line indicates of the time at which the colour change occurs, as nails grow approximately 0.10 to $0.15 \mathrm{~mm} /$ day [4]. The Wood's lamp is mostly used in dermatology and diagnosis of porphyria in medicine. The Wood's lamp is a source of UV radiation in the $320-400 \mathrm{~nm}$ spectrum with a peak at $365 \mathrm{~nm}$. It enables some substances that are not normally seen to be seen by using their fluorescent feature. Fluorescence happens because light absorbed in shorter wavelengths becomes visible when emitted at a longer wavelength due to excited electrons. Petrolatum-containing ointments are blue-purple fluorescent, drugs containing salicylic acid produce green fluorescence. With the use of oral tetracycline, a yellow fluorescence is seen in the lunula of the nail [5]. Quinacrine hydrochloride causes brilliant yellow-green fluorescence of the nails [6]. Vitamin B2 shows yellow-green fluorescence and quinine shows blue fluorescence [7].

All our patients had COVID-19 infection diagnosed with COVID-19 PCR. Except for the 1st patient who did not receive favipiravir treatment because his mother did not accept, all patients received favipiravir treatment for 5 days. We saw blue fluorescence in the nails in all patients who received favipiravir. The magnitude of this blue fluorescence was compatible with the time of receiving favipiravir therapy. There was no fluorescence in our patient with COVID-19 who did not receive favipiravir treatment. This blue fluorescence in the nail indicates that favipiravir treatment was received. Except for patient 6, all patients received oral or intravenous vitamin B complex and vitamin $\mathrm{C}$, as well as subcutaneous enoxaparin therapy. We did not observe that this treatment caused a difference in nail fluorescence. We observed a blue fluorescence affecting the entire nail plate of the second patient receiving antituberculosis treatment. We could not find any information that antituberculosis drugs cause nail fluorescence changes. Fluorescence in the nail due to favipiravir may be due to the active drug or excipients. We did not find any publications in our searches in medical databases for nail fluorescence due to favipiravir. We think that this finding is a simple method that can be used for the follow-up and evaluation of favipiravir intake in patients.

\section{References}

1. (2020) Shine on the nails of people who had corona attracted attention.

2. Sarker A, Ginn R, Nikfarjam A, Connor K, Smith K, et al. (2015) Utilizing social media data for pharmacovigilance: A review. Journal of biomedical informatics 54: 202-212.

3. Riley DS, Barber MS, Kienle GS, Aronson JK, Schoen AT, et al. (2017) CARE guidelines for case reports: explanation and elaboration document. Journal of clinical epidemiology 89: 218-235.

4. Cashman MW, Sloan SB (2010) Nutrition and nail disease. Clinics in dermatology 28(4): 420-425.

5. Limone BA, Meadows L (2017) The Wood's Light's Diagnostic Use in Dermatology. Journal of the Dermatology Nurses' Association 9(4): 211-215.

6. Kierland RR, Sheard C (1946) Fluorescence of nails from quinacrine hydrochloride. Journal of the American Medical Association 131(10): 809-810.

7. Patil DT, Bhattar SL, Kolekar GB, Patil SR (2011) Spectrofluorimetric Studies of the Interaction Between Quinine Sulfate and Riboflavin. Journal of Solution Chemistry 40(2): 211-223.

\section{Your next submission with Juniper Publishers} will reach you the below assets

- Quality Editorial service

- Swift Peer Review

- Reprints availability

- E-prints Service

- Manuscript Podcast for convenient understanding

- Global attainment for your research

- Manuscript accessibility in different formats

( Pdf, E-pub, Full Text, Audio)

- Unceasing customer service

\section{Track the below URL for one-step submission}

https://juniperpublishers.com/online-submission.php 